\title{
O que é autor de telenovela?
}

Marines Boncoski Brizola

Doutoranda em Letras na UniRitter Laureate International Universities.

E-mail: marinesbrizola@gmail.com

Marlene Gonçalves Mattes

Docente do Programa de Pós-Graduação em Letras da UniRitter - Laureate International Universities e Coordenadora do Gesla - Grupo de Estudos em Linguística Aplicada (UFC).

E-mail: marlenemattes@yahoo.com

Resumo: Os conceitos de autor, autoria, co-autoria, texto-obra-criação, bem como de escrita colaborativa e de telespectador-modelo são abordados neste artigo, no que se refere às telenovelas produzidas no Brasil. Assim, com base nas obras de Umberto Eco O Leitor Modelo (1969), Walter Benjamin $O$ autor como produtor (1994), Roland Barthes A morte do autor (1984), Antonie Campagnon O autor (1999), Motter Ficção e realidade: a construção do cotidiano na telenovela (2003), entre outros, e também com base na Legislação Brasileira de Direitos Autorais (2011) analisam-se os conceitos de originalidade e adaptação da obra literária para a teledramaturgia. A discussão sobre os conceitos sugere continuidade em estudos posteriores, já que não se esgota nas abordagens aqui consideradas.

Palavras-chave: autor; autoria; coautoria; escrita colaborativa; telenovela.
Abstract: This paper discusses concepts of author, authorship, co-authorship, textwork-creation and collaborative writing and model viewer in the field of soap operas produced in Brazil. Thus, based on Umberto Eco works The Reader Model (1969), Walter Benjamin The Author as Producer (1994), Roland Barthes The Death of the Author (1984), Antonie Campagnon The author (1999), Motter Fiction and reality: Construction Of Daily Life in the Soap Opera (2003), among others, and also based on the Brazilian Copyright Law (2011), it analyzes the concepts of originality and adaptation of the literary work for television drama. The discussion of the concepts suggests later studies, as is not limited to what has been considered here.

Keywords: author; co-author; authorship; collaborative writing; soap operas.

\section{INTRODUÇÃO}

De um modo geral, em âmbito mundial, o Brasil é reconhecido no meio televisivo pela escrita e produção de telenovelas. O país concentra diversos ícones da teledramaturgia, entre eles: Aguinaldo Silva, Antônio Calmon, Benedito Ruy Barbosa, Carlos Lombardi, Janete Clair, Jorge Amado, Gilberto Braga, Glória Perez, Maria Adelaide Amaral, Regina Braga, Ricardo Linhares, Sílvio de Abreu, Walcyr Carrasco, Walther Negrão, entre outros. Algumas telenovelas produzidas no Brasil se tornaram fenômenos internacionais, alcançando muitos interessados no tema.

Recebido: 03/05/2015

Aprovado: 19/10/2015 
O tema implica conceitos vários, dentre os quais procuraremos discutir questionamentos decorrentes como: o que significa autor-escritor de teledramaturgia? O que são coautores de telenovela? Como analisar o conceito de originalidade no caso das telenovelas? A obra do escritor o qual assina a telenovela constitui-se em criação individual ou obra coletiva? E, no caso, quem detém os direitos morais de uma telenovela? A quem cabe a autoria de telenovela? Estas são algumas das questões que este artigo pretende abordar.

\section{O QUE É TELENOVELA?}

A telenovela, ou mais popularmente novela, é o substantivo feminino de novelo, ou seja, o fio a ser desenrolado. Esse entretenimento constitui-se, conforme explica Renata Pallottini ${ }^{1}$, em:

[...] uma história contada por meio de imagens televisivas, com diálogo e ação, uma trama principal e muitas subtramas que se desenvolvem, se complicam e se resolvem no decurso da apresentação. Naturalmente a trama planejada como principal é a que leva o enredo básico, a fábula mais importante, do começo ao fim da ação, e a que justifica todo o projeto, dando-lhe unidade.

De modo geral, as telenovelas partem de uma história escrita por um autor que a assina. Tal obra parte de uma ideia ou fio condutor, podendo configurar-se em diversos gêneros como romance, drama, comédia, entre tantos outros. Partindo, portanto, da ideia-condutora escrita por um autor, o roteirista - ou o diretor - reescreve ou adapta a obra para a televisão, ou seja, conforme as linguagens próprias do meio televisivo. Pode-se dizer que há dois tipos de roteiros: o roteiro literário (uma novela de fulano de tal) e o roteiro técnico (uma novela escrita por fulano de tal e colaboradores).

O roteiro literário, segundo Jorge $\mathrm{Machado}^{2}$, "não contém indicações técnicas" (é a escrita do autor), enquanto o roteiro técnico "contém indicações técnicas" referentes a criação e desenvolvimento dos personagens e do enredo (nessa parte, incluem-se o roteirista e os pesquisadores, bem como câmeras, iluminadores, diretores de produção e mais inúmeros especialistas das mais diversas áreas do ramo televisivo). De modo geral, é o roteiro técnico que transforma o roteiro literário em uma obra ficcional comercializável (telenovela

1. PALLOTTINI, Renata. Dramaturgia de televisão. São Paulo: Moderna, 1998 , p. 35.

2. Disponível em: <www. roteirodecinema.com.br/ manuais/vocabulario. htm> Acesso em: 09 maio 2013.

3. Disponível em: <www. dicionariodoaurelio.com/ Autor.html> Acesso em: 21 maio 2013. em si). Vejamos então como conceituar quem escreve a própria obra.

\section{O QUE É AUTOR? O QUE É COAUTORIA?}

Com a adaptação de diversas obras literárias para a teledramaturgia, surge a figura do roteirista-escritor e assim deparamo-nos com a questão referente a autor versus autoria. Segundo o Dicionário Aurélio ${ }^{3}$, o conceito de autor é:

Aquele que está na origem de, que é a causa de: o autor de uma invenção. Aquele que faz uma obra literária, científica, artística. Direito de autor, direito 
exclusivo de exploração reconhecido a qualquer um sobre toda criação original que manifesta sua personalidade, nas letras, ciências ou artes. Direitos de autor, proventos recebidos por publicação de obra.

Ou seja, o conceito de autor funde-se com o conceito de originalidade que significa:

Relativo à origem; que remonta à origem; primitivo. Que parece produzir-se pela primeira vez; não copiado, não imitado. Que tem caráter próprio, que tem cunho novo e pessoal; que não segue modelo. Extraordinário, singular. Manuscrito primitivo, primeira redação de uma obra, de uma lei, decreto, livro etc. Obra de arte produzida por um artista. Modelo primitivo (por opos. à cópia). Texto primitivo (por opos. à tradução) ${ }^{4}$.

Ambos os conceitos remetem à ideia de uma obra individual, do processo criativo de um só autor. Em contrapartida, o conceito de adaptabilidade ou adaptação da obra literária corresponde à: "Transposição de uma obra literária para o teatro, televisão, cinema, etc. Arranjo, adequação de uma obra estrangeira que, além da tradução, implica modificações do texto original" ${ }^{5}$. Assim, obra individual teria ligação com os conceitos de autor-originalidade-indivíduo.

Considerando-se os conceitos acima, pergunta-se em que medida o conceito de autor poderia se estender a obras audiovisuais como telenovelas, por exemplo?

De modo geral, ao final da exibição de cada capítulo de uma telenovela, nos pós-créditos, identificam-se os escritores colaboradores. Para Nogueira ${ }^{6}$, os escritores colaboradores são coautores de telenovela, pois contribuem "na elaboração da sinopse" e escrevem "a telenovela junto com o autor principal", mas é o autor principal quem exerceria o "papel de liderança”, escrevendo e interferindo "na produção da telenovela". Todavia, como veremos a seguir na Lei $\mathrm{n}^{\circ}$ 9.610, de 19 de dezembro de 1998 (Capítulo II - Da Autoria das Obras Intelectuais, Art. 15) ${ }^{7}$ altera, atualiza e consolida a legislação sobre direitos autorais: " $\$ 1^{\circ}$ Não se considera coautor quem simplesmente auxiliou o autor na produção da obra literária, artística ou científica, revendo-a, atualizando-a, bem como fiscalizando ou dirigindo sua edição ou apresentação por qualquer meio". Haveria, portanto, a necessidade se tornar claro, à luz do texto legal, o que se define como autoria de sinopse e colaboração na produção da obra literária, artística ou científica. Parece-nos não se tratar nem da mesma tarefa, nem da dimensão do impacto que possa vir a ser causado no texto original (texto da novela). Dessa forma, a questão parece merecer uma discussão já na base, na fundamentação das ideias essenciais que direcionam a compreensão do fato aqui tratado.

\section{O QUE É SER AUTOR/COAUTOR EM OBRA AUDIOVISUAL?}

Hermano Duval ${ }^{8}$, estudioso dos direitos de autoria explica que:

4. Idem, ibidem.

5. Idem, ibidem.

6. NOGUEIRA, Lisandro. O autor na televisão. Goiânia: Ed. UFG; São Paulo: Ed. Edusp, 2002, p. 82.

7. BRASIL. Legislação sobre os direitos autorais. 4. ed. Brasília. Senado Federal. Subsecretaria de Seções Técnicas, 2011.

8. DUVAL, Hermano. Obra Comum ou em Colaboração. In: SANTOS, João Manoel de Carvalho (coord.). Repertório Enciclopédico do Direito Brasileiro. V. XXXV. Rio de Janeiro: Borsoi, 1947, p. 01. 
[...] um colaborador teve uma ideia, mas não sabe desenvolvê-la; outro, tem um plano, mas não tem ideia; um terceiro tem o estilo, que falta aos dois primeiros; finalmente, um quarto tem uma "saída" para um desfecho feliz de um romance, peça teatral, drama ou obra cinematográfica, mas falta-lhe tudo o que os outros têm [...] reúnem-se todos e conjuntamente elaboram a obra, que resulta comum, pois a permuta de ideias e de inspirações também leva à obra comum. Todos, pois, são coautores ou colaboradores pro indiviso: pelo todo e pela parte.

A inferência possível, acerca do acima exposto, é a de que o conceito de autor, em obra coletiva, poderia vincular-se ao conceito de coautoria. No entanto, segundo pontua a Lei $\mathrm{n}^{\circ}$ 9.610, de 19 de dezembro de 1998, artigo 16: "São coautores da obra audiovisual o autor do assunto ou argumento literário, musical ou lítero-musical e o diretor", perspectiva segundo a qual o diretor seria quem recebe o título de coautor, e, na sequência, "coautores da obra intelectual exercerão, de comum acordo, os seus direitos, salvo convenção em contrário" (artigo 23). Mas, no que se refere aos direitos morais do autor de obra audiovisual, o artigo 25 esclarece que: "Cabe exclusivamente ao diretor o exercício dos direitos morais sobre a obra audiovisual" e, no caso, também a responsabilidade pelo que foi produzido. Segundo a mesma lei, em seu artigo 24, são direitos morais do autor, dentre outros, os seguintes direitos: "I - o de reivindicar, a qualquer tempo, a autoria da obra" e "V - o de modificar a obra, antes ou depois de utilizada”. Em alguns casos de obras audiovisuais, pode haver um acordo de cavalheiros entre o diretor e o autor empírico. Segundo esse acordo, o diretor geralmente se abstém, em tese, dos direitos morais, para que o autor empírico possa ser reconhecido como o autor moral da obra, porém, juridicamente, o diretor é o detentor moral da obra audiovisual.

Observe-se que, de modo geral, o diretor depende do escritor empírico para a produção de suas obras e o autor empírico depende do diretor e da produtora (emissora de comunicação televisiva) para a veiculação de sua obra no meio televisivo. Segundo Alves Filho':

[...] a noção de autor refere-se à instância humana ou institucional a quem se atribui a macro-responsabilidade por um texto ou uma obra, e cuja contraparte verbal é um nome próprio (ou uma assinatura). Já o termo autoria refere o processo de atribuição, responsabilização e enunciação de um texto ou uma obra, de modo que mesmo aos textos que são destituídos de autores pode ser atribuída autoria. A um texto, por exemplo, que circula anonimamente, isto é, sem identificação do seu autor, pode ser suposta e atribuída uma dada autoria.

9. ALVES, FILHO F. A autoria nas colunas de opinião assinadas da FoIha de São Paulo. Tese de doutorado. Universidade Estadual de Campinas, Instituto de Estudos da Linguagem. Orientador: Ingedore Villaça Koch. Campinas, SP: [s.n.], 2005, p. 67.

10. Idem, ibidem.
Em obras audiovisuais, os conceitos de autor e autoria parecem imbricados. De modo geral, na televisão o texto (do autor empírico) subsiste e as imagens (produzidas pelos roteiristas, adaptadores ou diretores) prevalecem, sendo o próprio trânsito da página (escrita do autor) para a televisão (linguagem televisiva) guiado pelo que está na tela, segundo os índices de audiência. É como se o autor empírico, conforme coloca Alves Filho ${ }^{10}$, circulasse anonimamente com identificação de seu autor, porém sem que este possua os direitos morais 
da obra audiovisual, já que eles, segundo a legislação ${ }^{11}$, são atribuídos exclusivamente ao diretor.

Parece-nos que, se a obra original é passível de alterações, adaptações ao meio televisivo, naturalmente perde, possivelmente em parte, atributos de sua originalidade, restando, portanto, plenamente discutível a questão da atribuição de direitos morais a um ou a outro autor na perspectiva aqui mencionada.

\section{O QUE É PROCESSO CRIATIVO VERSUS OBRA TELEVISIVA?}

A linha de pensamento que vimos discutindo até aqui nos conduz à explicitação tanto do que se pode compreender acerca de processo criativo, quanto do como ele se configura na obra televisiva.

O escritor Jorge Amado, em entrevista à revista Domingo do Jornal do Brasil (Número 972, 18/12/1994), explicou a diferença entre obra de criação de um autor e obra escrita para a televisão:

Uma coisa é um romance, um livro. Você lê. Outra coisa é um filme ou uma obra de TV, que você vê. Um romance é um trabalho artesanal, uma obra de TV é industrial. Quando eu faço romance, sou eu que arranco aquilo da minha cabeça, do meu coração, das minhas tripas. Para fazer uma novela, você tem o produtor, o diretor, o diretor de atores, o operador, não sei quantos atores.

O escritor Manoel Carlos (a exemplo de Jorge Amado) expressou em entrevista à revista $V e j a^{12}$ que escreve sobre o que conhece. Ao ser questionado sobre sua rotina de trabalho, respondeu que:

Não tenho nenhuma rotina. Não tenho hora para escrever, hora para dormir nem hora para comer. Tenho um sono muito leve e, quando acordo no meio da noite, é comum que a novela venha inteira na minha cabeça. Aí eu me levanto e vou trabalhar no meio da madrugada. É como se fosse uma doença que toma conta de você, não dá para pensar em outra coisa. Mas não perco o contato com a minha família em hipótese alguma, e não deixo de ler seis jornais por dia.

A seguir, conforme a entrevista concedida pelo autor em questão, tratamos da influência da sua rotina no processo criativo de escrita. Quando o autor revela escrever sobre o que conhece e em seguida afirma ler seis jornais por dia, pode estar sugerindo que sua escrita advém das notícias que estão sendo retratadas cotidianamente pela sociedade. $\mathrm{O}$ autor também foi indagado pela revista sobre sua rotina e marcas de escrita:

Revista Veja: Uma das marcas de suas novelas é a atualidade dos diálogos, a rapidez com que expressões cotidianas de um grupo etário ou social são transpostas para a televisão. Como o senhor se abastece das informações necessárias para conseguir esse resultado?

11. BRASIL, op. cit.

12. Disponível em: $<$ http://veja.abril.com. br/090703/p_075.htmls. Acesso em: 04 maio 2013. 
13. BAKTHIN, M. (1979) Estética da criação verbal. Trad. Paulo Bezerra. São Paulo: Martins Fontes, 2006, p. 3.

14. BARTHES. Roland. A morte do autor. In: $O$ rumo da língua. Lisboa: Edições 70, 1984, p. 51.

15. Idem, ibidem.

16. Disponível em: $<$ http://veja.abril.com $\mathrm{br} / 090703 /$ p_075.html $>$. Acesso em: 04 maio 2013.

17. ECO, Umberto. O leitor modelo. São Paulo.

Perspectiva, 1969

18. SARLO, Beatriz. Zapping. In: ___. Cenas da vida pós-moderna: intelectuais, arte e vídeo-cultura na Argentina. Rio de Janeiro: UFRJ, 1997, pp. 57-58.
Manoel Carlos: Levo uma vida absolutamente normal. Vou a banco, entro em fila de casa lotérica e frequento feira e bancas de jornal. Ando pela rua e converso com as pessoas. É assim que assimilo as diferentes expressões. A Globo é uma torre de marfim, de onde as pessoas costumam sair pouco. Já eu saio todos os dias, mesmo fazendo novela. Só não posso ir ao cinema, porque me atrapalha. Também não leio romances, quando estou escrevendo.

O processo de criação "do-ser-estar-autor-de-telenovela", mencionado por Jorge Amado e Manoel Carlos, parece se relacionar com o processo de criação posto por Bakthin ${ }^{13}$ :

[...] vivencia o trabalho criador, mas o vivenciamento não escuta nem vê a si mesmo, escuta e vê tão-somente o produto que está sendo criado ou o objeto a que ele visa. Por isso, o artista nada tem a dizer sobre o processo de sua criação, tão situado no produto criado, restando a ele apenas nos indicar a sua obra; e de fato é aí que iremos procurá-lo.

Ao que parece, o processo de criação não se deixa apreender e os autores de telenovela não precedem ao texto, eles se constroem na inscrição subjetiva do texto e depois se ausentam. Durante a trama, abstrai-se o autor e exaltam-se os atores-personagens, por sua vez, com suas próprias leituras da obra e, por último, os telespectadores com mais outras possibilidades para a leitura. Nesse sentido, o texto de telenovela pode revelar o autor como um personagem moderno, produzido pela sociedade e, conforme conceitua Barthes ${ }^{14}$ :

$\mathrm{O}$ autor moderno nasce ao mesmo tempo que seu texto; não está de modo algum provido de um ser que precederia ou excederia a sua escrita, não é de modo algum o sujeito de que o seu livro seria o predicado, não existe outro tempo além do da enunciação, e todo texto é escrito eternamente "aqui" e "agora".

O escritor Manoel Carlos afirmou, na entrevista mencionada acima, que "se a novela não dá certo, terá de carregá-la nas costas", ou seja, se de alguma forma a obra torna-se um cadáver ${ }^{15}$, o seu autor revive, e então, ele terá de assumir o lado ruim da assinatura do texto. É significativo perceber que, mesmo não possuindo os direitos morais pela obra audiovisual, Manoel Carlos assume para si essa responsabilidade: "sou eu o criador da ideia-condutora do drama". Ainda, na mesma entrevista, Manoel Carlos afirma que:

Quando entra uma cena que considero lenta, anoto o minuto exato em que ela foi ao ar, para conferir no medidor de audiência que tenho em casa como foi o ibope. Novela é uma surpresa. Às vezes não assisto a um capítulo porque acho que ficou tão ruim que tenho vergonha. Mas não é raro que as pessoas gostem do que não gosto ${ }^{16}$.

Estaria o autor empírico afirmando estar submetido ao telespectador-modelo? Ao que parece, o teledramaturgo tem consciência de que escrever para televisão é escrever para o que, em vez de chamarmos de leitor-modelo ${ }^{17}$, poderíamos denominar telespectador-modelo. Mas, afinal, o que seria telespectador- modelo? Segundo Sarlo ${ }^{18}$, o uso do controle remoto é manuseado conforme as leis que a própria televisão ensinou a seus espectadores mediante: 
[...] fabricação acumulada de imagens impactantes; alto ou baixo nível de informação com velocidade superior à capacidade do telespectador de reter seus conteúdos; fuga da pausa e da retenção do fluxo de imagens; variada repetição do conteúdo; ausência de silêncio; movimentação contínua das câmeras, combinação de planos breves, preenchendo o vídeo de imagens, para tentar evitar a mudança de canal.

No caso das telenovelas, os diretores transformam a escrita do autor empírico em roteiro técnico, e os atores, por sua vez, buscam individualmente chegar a um processo de fruição para então construírem seus personagens. Umberto Eco $^{19}$, com o exemplo do compositor e do intérprete, elucida como se dá este processo de leitura do intérprete:

Entre as recentes produções de música instrumental podemos notar algumas composições assinaladas por uma característica comum: a peculiar autonomia executiva concedida ao intérprete, o qual não só dispõe da liberdade de interpretar as indicações do compositor conforme sua sensibilidade pessoal (como se dá no caso da música tradicional), mas também deve intervir na forma da composição, não raro estabelecendo a duração das notas ou a sucessão dos sons, num ato de improvisação criadora.

Umberto Eco, em Obra aberta $(1969)^{20}$, ajuda-nos a analisar a telenovela, quando diz que: "obras inacabadas, que o autor, aparentemente desinteressado de como irão terminar as coisas, entrega ao intérprete mais ou menos como as peças soltas de um brinquedo de armar”. Segundo Benjamin ${ }^{21}$, os leitores estão sempre prontos "a escrever, descrever e prescrever". No caso das telenovelas, podemos pensá-las como diversas releituras do texto, visto que o texto do autor empírico passa pela leitura dos atores e, enquanto ator-leitor, constrói seu personagem segundo esta leitura e, no caso dos telespectadores, haverá um novo processo de (re)leitura.

\section{O QUE DIZ O ATOR ATRAVÉS DO PERSONAGEM?}

Basicamente, pela leitura do ator é construído um personagem a ser interpretado. A partir daí, as telenovelas em si, ao que parece, têm construído identidades (femininas, masculinas, juvenis, sexuais, étnicas, religiosas etc.). Segundo Motter ${ }^{22}$ :

A telenovela pode ser considerada, no contexto brasileiro, o nutriente de maior potência do imaginário nacional e, mais que isso, ela participa ativamente na construção da realidade, num processo permanente em que a ficção e realidade se nutrem uma da outra, ambas se modificam, dando origem a novas realidades, que alimentarão outras ficções, que produzirão novas realidades.

Na concepção do autor em questão, telenovelas podem construir projetos de realidades, espaços nos quais se narra o real, mas também nos quais se constroem realidades. De modo geral, as telenovelas podem ser consideradas propagadoras de modelos identitários, nos quais a obra ausenta seu autor. Para
19. ECO, Umberto. Obra aberta: forma e indeterminação nas poéticas contemporâneas. São Paulo: Perspectiva, 1969, p. 37.

20. Idem, p. 41.

21. BENJAMIN, Walter. $\mathrm{O}$ autor como produtor. In:___._. Magia e técnica, arte e política. 7. ed. Trad. de Sérgio Paulo Rouanet, São Paulo: Brasiliense, 1994, p. 115. [Obras Escolhidas, v. 1].

22. MOTTER, Maria Lourdes. Ficção e realidade: a construção do cotidiano na telenovela. São Paulo: Alexa Cultural, 2003, p. 174. 
23. BURKE, P. Hablar y callar. Funciones sociales del linguaje a través de la historia. Trad. Alberto L. Bixio. Barcelona: Gedisa, 2001, p. 16.

24. SCHNEIDER, M. Ladrões de palavras: ensaio sobre o plágio, a psicanálise e o pensamento. Trad. Luiz Fernando P.N. Franco. Campinas: Editora da Unicamp, 1990, p. 20.

25. CAMPAGNON, Antoine. $O$ autor. In: O Demônio da teoria: literatura e senso comum. Belo Horizonte: Ed. UFMG, 1999, p. 51.
Burke $^{23}$, o texto torna-se ficção. Para Schneider ${ }^{24}$, através da atuação dos atores, a realidade do telespectador pode se tornar a ficção real.

Conforme Campagnon ${ }^{25}$, "o leitor, e não o autor, é o lugar onde a unidade do texto se produz, no seu destino, não na sua origem”. Nesse sentido, as telenovelas mais que entretenimento revelam formas de organizar, ver e interpretar a realidade. Pelos personagens veiculam-se valores morais, éticos, comportamentais, que podem ser incorporados coletivamente pela sociedade telespectadora. A persuasão do telespectador pode acontecer pela identificação com os personagens (atores) que, na maioria das vezes, podem ser cópias convincentes de personagens da vida real (embora, a maioria das telenovelas nos pós-créditos advirtam o não compromisso com a realidade, sendo qualquer semelhança mera coincidência).

\section{CONSIDERAÇÕES FINAIS}

Este estudo, tendo abordado os conceitos de autor/coautoria, texto-obra-criação, em relação às telenovelas, procurou analisar, em específico, a questão acerca de que ser autor de telenovela parece exigir, antes de mais nada, a análise do que é telespectador-modelo. Cada autor de telenovela, conforme a faixa de horário em que a novela é transmitida, parece reconhecer as características de seu telespectador-modelo. Dentre os conceitos tratados, constata-se também que o diretor das obras audiovisuais detém dos direitos morais. A autoria de telenovelas está vinculada a um ou mais autores empíricos e, simultaneamente, a um ou mais diretores, adaptando a obra empírica a uma linguagem televisiva e, finalmente, a telenovela produzida será veiculada pela emissora detentora dos direitos autorais. Inevitavelmente, na escrita televisiva, o autor empírico morre, mas sua presença pode ser percebida em suas marcas de linguagem.

A leitura das obras de base permite perceber que a conceituação definida, neste âmbito de estudo, parece carecer de uma explicitação mais específica, por exemplo, no que se refere a noções de adaptabilidade, transposição, escritores colaboradores, autor principal; bem como da relação entre conceitos e entre funções (de quem cria a obra, quem a adapta, quem a altera, quem a recria - por assim dizer).

Concluindo-se, pode-se afirmar que as telenovelas exercem um compromisso além do entretenimento, gerando também a necessidade do aprofundamento de algumas questões teóricas referentes à escrita televisiva, como: o que cada telenovela objetiva expressar em sua faixa de horário de transmissão e em que medida a atuação do ator faz de seu personagem um modelo de identidade a ser seguido pelos telespectadores. Tais questões foram mencionadas com a devida limitação a artigo, contudo sem a profundidade que caberia ao tema em espaço maior; ratificando-se, portanto, que haja continuidade em estudos posteriores. 


\section{REFERÊNCIAS BIBLIOGRÁFICAS}

ALVES, FILHO F. A autoria nas colunas de opinião assinadas da Folha de São Paulo. Tese de doutorado. Campinas, Unicamp, 2005.

BAKTHIN, M. (1979). Estética da criação verbal. Trad. Paulo Bezerra. São Paulo: Martins Fontes, 2006.

BARTHES. Roland. A morte do autor. In: O rumo da língua. Lisboa: Edições 70, 1984.

BENJAMIN, Walter. O autor como produtor. In: Magia e técnica, arte e política. 7. ed. Trad. de Sérgio Paulo Rouanet, São Paulo: Brasiliense, 1994, p. 115. [Obras Escolhidas, v. 1].

BRASIL. Legislação sobre os direitos autorais. 4. ed. Brasília. Senado Federal. Subsecretaria de Seções Técnicas, 2011.

BURKE, P. Hablar y callar. Funciones sociales del linguaje a través de la historia. Trad. Alberto L. Bixio. Barcelona: Gedisa, 2001.

CAMPAGNON, Antoine. O autor. In: . O Demônio da teoria: literatura e senso comum. Belo Horizonte: Ed. UFMG, 1999.

DUVAL, Hermano. Obra Comum ou em Colaboração. In: SANTOS, João Manoel de Carvalho (coord.). Repertório Enciclopédico do Direito Brasileiro. V. XXXV. Rio de Janeiro: Borsoi, 1947.

ECO, Umberto. O leitor modelo. São Paulo. Perspectiva, 1969.

. Obra aberta: forma e indeterminação nas poéticas contemporâneas. São Paulo: Perspectiva, 1969, p. 37.

MOTTER, Maria Lourdes. Ficção e realidade: a construção do cotidiano na telenovela. São Paulo: Alexa Cultural, 2003.

NOGUEIRA, Lisandro. O autor na televisão. Goiânia: Ed. UFG; São Paulo: Ed. Edusp, 2002.

PALLOTTINI, Renata. Dramaturgia de televisão. São Paulo: Moderna, 1998.

SARLO, Beatriz. Zapping. In:___ Cenas da vida pós-moderna: intelectuais, arte e vídeo-cultura na Argentina. Rio de Janeiro: UFRJ, 1997.

SCHNEIDER, M. Ladrões de palavras: ensaio sobre o plágio, a psicanálise e o pensamento. Trad. Luiz Fernando P.N. Franco. Campinas: Editora da Unicamp, 1990. 